\title{
Urban community: modern understanding and value for participants
}

\author{
Vera Orlova ${ }^{1, *}$ \\ ${ }^{1}$ Tomsk State University of Control Systems and Radioelectronics, Russia
}

\begin{abstract}
Since the 19th century - the period of the destruction of the traditional way of life, urbanization, mass migration, the formation of new directions and entire scientific disciplines - the city and society have become objects of close study of representatives of existing and newly emerging areas of science. "Community" is becoming one of the most popular concept of sociological language. Communities are considered in the context of urban development. The foundations of occurrence, modern understanding and significance for participants in urban communities are revealed. The object of the study is the global community of young people, acting in the city of Tomsk as an initiative of the World Economic Forum. The subject is the grounds for the formation and reasons for young people to enter the community. The subject is the grounds for the formation and reasons for young people to enter the community. The urban community is considered as a significant agent in complex processes (economic, political, social, cultural, etc.), in which today, without exception, all city residents are involved. Important facts highlighted for studying the phenomenon of urban communities.
\end{abstract}

\section{Introduction}

Western sociology, urban studies, anthropology have advanced far in the study of the phenomenon of urban communities. Today, there are many theories that not only trace the historical development of this phenomenon, analyze the relationship of micro- and macroprocesses that influence the formation and development of communities within a city, but also sometimes offer completely alternative ideas about the role of communities in a modern city.

It is the urban community that is considered as a significant agent in complex processes (economic, political, social, cultural, etc.), in which today all residents of cities are involved without exception. At the same time, many modern sociologists are unanimous in their opinion that the community is becoming an important player not only in domestic and urban processes, but also on the international stage. Since it is the city today that is considered as an important object involved in the processes of globalization. Jeanette Sadic-Khan, Commissioner of the New York Department of Transportation, notes that cities are part of the global market. For the first time in history, the majority of the world's population lives in

\footnotetext{
* Corresponding author: orlova_vv@mail.ru
} 
cities, and, according to UN forecasts, the number of inhabitants of the Earth will double in the next 40 years. Cities need to try to attract residents and make their life comfortable.

As the organizers of the community note, today more than $50 \%$ of the world's population is under the age of 27, most of whom live in urban areas. In a study conducted by the headquarters of the World Economic Forum, it turned out that $92 \%$ of the respondents from different parts of the Earth in the corresponding age range agree that the world must change, $84 \%$ consider it their duty to make these changes, almost $82 \%$ believe that they have the power and capacity to make these changes real. In addition, as the authors of the study point out, this generation feels more confident due to the existing technological opportunities for obtaining information and, as a result, increased opportunities for interaction and cooperation with other people.

Our assumption is that the theme of urban communities today is no less relevant than in previous decades: they continue to be studied and considered in the context of urban development. Residents of the city cooperate in such associations due to the understanding of the importance of people interacting with each other for the implementation of initiatives and their own development.

Ferdinand Tennis in his theory introduced distinctions between the concepts of "community" and "society". The basis of this division is the difference between the concepts of "familiar" and "alien". Tennis singled out the communities that are formed due to consanguinity, the neighboring communities and the citizens of the city welded together by friendship as political units. It is worth noting that Ernst Trelch, Emil Durkheim, Friedrich A. von Hayek and Karl Popper and others based on this theory of Tennis - the distinction between the basic concepts of "community" and "society".

Modern Russian scientists who study the problems of the internal life of the city and the territorial organization of society focus on the direct relationship between the socio-economic development of the city (or the region as a whole) and the presence of formalized local communities on this territory. Despite the fact that social stratification is being formed in the city, various social roles of the population are recorded and divided, which are reflected in various aspects of the life of citizens, and are determined by the organization of the division and opposition of functional spaces. In particular, the urban community is understood as "a special socio-territorial group of the population existing in indissoluble unity with the natural and artificial environment of its habitat, with specific mechanisms of functioning and development. The fundamental point is precisely the inseparability of the socio-territorial group and its environment, when changes in one element inevitably entail changes in others.

At the same time, the main characteristics of this kind of urban associations are: relative self-sufficiency, awareness by residents of their belonging, the presence of common interests, homogeneity of the community, intensity of internal contacts, social solidarity. In addition, the reproduction of human capital as a carrier of recreational conditions at the individual and aggregate level is impossible outside its environment.

What is the Global Shapers Community? The basis of the community is the so-called hubs (hubs) in the capitals and large cities of most countries of the world, uniting young people who want to contribute to improving life at the local level. Each hub has its own curator-founder. The task of a local hub is to be a full-fledged participant in regional and global processes and a catalyst for entrepreneurship. Hub Participants - Shapers are involved in projects related to specific issues identified by both the local hub and the Global Shapers Community. Projects are discussed at regular meetings held in regions of the world and in the EEF headquarters. But, most importantly, projects and the hub as a whole should have an impact and improve the life of the city and the region.

To become a member of the local Global Shapers Community, its creators have developed a number of conditions (entry procedures, characteristics that potential shapers should have, etc.). In particular, these include:• Age: from 20 to 30 years old; $\bullet$ Having high standards of 
moral and mental integrity; $\bullet$ The presence of unique qualities that distinguish it from the mainstream; Experience in the entrepreneurial field (experience in project implementation, founding a company or organization); $\bullet$ Willingness to participate in the life of the community, reinforcing their mission and goals to support their fellow Shapers in personal and professional development.Representatives of any profession can become members of the GSC, aimed at developing their abilities in the interests of society. They should be supporters of high moral and intellectual principles. Members of the Global Shapers Community organize centers of activity in major cities of the world - they interact with each other, exchanging experiences and ideas. By communicating with each other, the members of the Community can put forward ideas and entrepreneurial innovations to solve pressing global problems: from improving legislation and the environment to employment of young people. To put their ideas into practice, Community members can use the forum's platform and opportunities for cooperation with companies that are strategic partners of the WEF.Today, the Global Shapers Community has a large network of hubs around the world - 322 hubs and more than 3.5 thousand shapers. There are 11 hubs in Russia. Tomsk joined the global initiative in 2013 and became the 7th city in Russia.

\section{Methods}

The subject of our study is the basis for the emergence and entry of people into new social relations - communities that have a significant role in the life and development of the city, its citizens. As follows from the theory, throughout the entire period of studying the topics of society, communities and urban development, new ones appeared, the old principles of the formation and operation of such associations, the involvement of residents at different stages of the internal and external development of the city, region, etc., were modified also the main characteristics of existing communities. For the study, a semi-structured interview method was chosen. Interviews were conducted between April and May 2014.

Based on the results of the study, we will try to characterize the Global Shapers Community from the inside, determine its main parameters and the reasons why this community today represents one of the most widespread networks around the world.First of all, we need to determine the internal structure of the device and regulation of the life and activities of the hub. As noted in the paragraph above, each local (or city) hub has its own curator-founder. In interviews, respondents noted that the curator acts as an experienced mentor for them. Answering the question about the role of the curator, the shapers singled it out as important, setting the direction of the hub's movement, an important point for them is the experience of implementation and participation in complex projects. From an interview: "Thanks to her (curator's note) experience and professionalism, we have more opportunities to implement our own ideas."As for the internal hierarchy of the Tomsk community, 2/3 of the respondents noted the "horizontal" type of building relationships. "It's definitely not a vertical structure. It's generally accepted that curators don't dictate what the hub should do. It all comes proactively from the shapers. "'You can do different projects, you can implement anything. At the same time, of course, there are limitations, but still freedom is characteristic. We are free in our development. We can choose our own line of development, our hub, and move in this direction. "Here we can see the difference from the classical perception of the community in Tennis theory, as an exclusively hierarchical model, where each member is assigned his own role and functions. Despite the presence, at first glance, of a hierarchical structure of the community - there is a creator, curators and shapers themselves - interaction within each community takes place at a partner, non-coercive and non-punishable level. Touching upon the topic of the internal structure, the respondents cited as an opposite example the professional communities that also operate in the city and beyond. "There is a strict hierarchy. Moreover, there is an official and not quite official hierarchy. Unfortunately, 
I don't know if this is right or wrong, but I have to live within this hierarchy. And not always, for example, some of your own, as it seems to you, promising ideas or thoughts find support. "As far as the reasons for joining this community are concerned, there are also some interesting points. Note that the Tomsk hub (like everyone else around the world) includes representatives of a wide variety of areas of activity - from IT to road construction. As the main reasons for joining the community, respondents noted: Interest in different kinds of communities "I am also interested in interesting communities, I am constantly interested in what is happening in the city, in various social projects". Desire to pass on your knowledge / skills / abilities to others and use them to improve life around "I've always tried to teach someone something, transfer knowledge, etc. One of the aspects of my success is that someone taught me something, someone believed in me, and it is important for me to pass it on. It was one of the most important factors in which I agreed to join the community, because I am very sympathetic to the goals and positioning of GSC. "• Involvement in global processes "It's such a pleasant feeling that you don't seem to know these people, but you have a few acquaintances in other cities who, if anything, will help you at least on the principle that you are in this community". "The desire to make our city better, to do something small but good for the whole world, the desire to join the international young network of world leaders, to have the opportunity to interact with youth leaders from all over the world, the desire to open our country to the whole world, to improve the economic the situation in our country, to improve the image of cities and regions of Russia. The Global Shapers Community is a constant interaction with people from various countries, we represent not only ourselves here, we represent our cities and our country. We give people the opportunity to improve what they do, develop in the professional sphere, improve the sphere of contacts, find new partners, new friends, colleagues, gain new international experience, share their experience. That is, it is a global online platform. "This is some kind of big system and somehow it became interesting to feel like a small grain of something huge, you understand that you are not just doing something here in Tomsk, but that with similar things, or not similar, but some others are engaged all over the world ... but it is participation in this community that makes it possible to talk about even the "smallest" business, in quotes, of course, because there are no "small" cases". Opportunity to receive feedback / advice / opinions from professionals from other fields "At least at the level of advice, which is also important for me, I reviewed a lot for myself. Over the past six months I have done.

According to the theory of Tennis, the concepts of "community" and "society" mean opposite forms of human community. By an ideal community, he understood significant interpersonal relationships based on family ties. Community-typical interhuman relationships rest on "natural" morality. From the point of view of political domination, these are hierarchical orders, which in history developed primarily as patriarchy and sometimes as matriarchy. From a social point of view, these are associations based on a common tradition and a common religion. In general, the axiom of F. Tennis's theory is that the identity of the community is rooted in the emotional connection of its members.

In contrast to the ideal type of "community", the ideal type of "society" means "openness", which Tennis defines as "human aggregate and artifact. As an "open" subject, there is "everyone alone and in a state of conflict with all others." There is a general opportunity to compare items as a "product". The ability to compare is expressed in the existence of money as a measure of exchange. Interhuman relations in a "society" are based on contractual obligations, that is, on a convention. In contrast to the "natural" connections of the "community", "artificial" mutual responsibilities and dependencies are developed. Tennis proceeds from the fact that the sharp contrast between the "community" and "society" exists only on a conceptual and ideotypical basis.

We can distinguish a number of characteristics that communities have, according to F. Tennis's theory: 
- The reason for the occurrence: consanguinity, the neighborhood community, and "citizens welded together by the friendship of the citizens of the city as political units".

- The structure of the community is hierarchical, like a family structure.

- Community forms: political, social, and economic.

- There are two classes of norms of cooperative morality on which the life activity of communities is built: norms to which everyone obeys, and norms determined by the steps of the social hierarchy.

- A person in a community is not considered as an individual, but as the social role that he performs.

Contemporaries of Ferdinand Tennis - sociologists Emil Durkheim and Max Weber - also draw attention in their works to the problems of the structure of society and individual communities, as an integral part of the functioning and interaction of people (and citizens in particular) among themselves.

By fixing and exploring this type of connection as solidarity, E. Durkheim gives us the opportunity to consider the communities and the grounds for their emergence, based on various forms of solidarity. In particular, the French sociologist makes a distinction between mechanical solidarity, where the community is based on the similarity of people to each other, and organic, characteristic of complex societies, where people are different from each other, and each group performs its function in a single social organism. But in both cases, the basis of solidarity is the so-called solidifying action of the division of labor, which is, however, not realized automatically, but with the help of special mechanisms of social regulation that create a "moral community" that is basic for solidarity relations.

According to Weber, the structure of any legal order directly affects the distribution of economic or any other power within the respective community. Classes, status groups and parties are phenomena related to the distribution of power within a community.

The end of the 19th and the beginning of the 20th century is a period of social and political transformations in Europe and America, when industry becomes the leading sector of the economy, new production technologies appear. This entails the rapid consolidation of the industrial enterprises themselves - factories and factories. There is a demand for labor. Residents of villages and surrounding areas move to cities, becoming full participants in urban life. The increase in the number of people in the territory shows the need to expand existing and the emergence of new cities, their territorial and social facilities, including urban "heavy" (roads, cars, railways, etc.) infrastructure, places for recreation and entertainment, shopping, education, etc. The processes of urbanization are actively taking place, which leads to the formation of new types of relations and forms of settlement of urban residents. It was during this period, as a number of authors fixes, that a number of changes occurred concerning a single person: the status of a person ceased to be given by birth and was the result of individual achievements, a person began to be considered as a separate person.

The more complicated processes "bared" and made relevant the issue of interaction between "friends" and "strangers". The theory of the German sociologist Tennis and its basic distinction "friend / foe" has become a starting point for other areas and directions of the study of communities. In particular, community studies, in which anthropology and German classical sociology are combined, are based on the theory of the interaction of "one's own" and "another's". In her book, "The City in Theory: Experiences in Understanding Space," Elena Trubina identifies a number of problems related to the development of the study of urban space, the urban environment, and the inhabitants of individual cities posed by 19thcentury scientists. Note some of them:

- Does urban lifestyle contribute to the emergence of new social groups and identity options?

- How does urban life affect traditional social relations, which are based on respect for the owners of the "higher" class, gender, caste or racial status? 
- Does the city contribute or hinder the formation of social ties between people of different origin, place of residence and occupation?

Representatives of the Chicago School of Sociology Robert Park and Ernest Burgess noted that the community refers to a type of population that is either determined by its geographical location, or by common place of residence and work. It was during this period that the two key characteristics of communities, united among themselves, are most clearly manifested - people and territory.In this regard, Robert Park defines the community as a collection of people occupying a more or less clear area, but not just a collection of people, but a collection of institutions, since it is the institutions and not the people that are the final and decisive factor that distinguishes the community from other social constellations.

One of the most successful modern theory of representing the internal structure of urban life and city residents is the theory of the famous American economist Richard Florida, whose main thesis is that the types of communities that guarantee economic prosperity have changed significantly by now.

According to Florida, traditional ideas about a cohesive society tend to stifle economic growth and innovation. Close ties in families and between friends, close relations between neighbors, civic associations, a dynamic electoral policy, strong religious institutions and reliance on civic leadership are leaving, and the so-called "creative class" is being replaced. Florida claims that the classical idea of the benefits of the interaction of people in the same group (community) is losing its relevance, as social interactions in cities begin to be minimized, the reason for which is the rapid information and technical development and decrease in the value of such interaction. Moreover, the transition from small homogeneous communities with strong ties to larger communities with weakened ties is a fundamental fact of modern history.

Modern Russian scientists who are studying the problems of the internal life of the city and the territorial organization of society focus on the direct relationship between the socioeconomic development of the city (or the region as a whole) and the presence of formalized local communities on this territory. Despite the fact that social stratification forms in the city, various social roles of the population are fixed and shared, which are reflected in different aspects of the life of citizens, and are determined by the organization of the separation and opposition of functional spaces.

In particular, urban community is understood as "a special socio-territorial group of the population that exists in inextricable unity with the natural and artificial environment of its habitat, with specific mechanisms of functioning and development. The fundamental point is precisely the inextricability of the socio-territorial group and its environment, when changes in one element inevitably entail changes in others. "At the same time, the main characteristics of this kind of urban associations are: relative self-sufficiency, residents' awareness of their belonging, common interests, homogeneity of community, intensity of internal contacts, social solidarity. In addition, the reproduction of human capital as a carrier of recreation conditions at the individual and aggregate level is impossible outside its environment.

Thus, it is important to note that the evolutionary nature of the formation of communities, caused by natural processes in cities, had a significant impact on the development of entire spheres of people's lives - social, cultural, economic, etc. Each member of such a community, which arose and acted within certain boundaries, became an active participant in such changes, and in the first place, benefited from it. Moreover, each community was a complex device with its own internal norms, rules, and ideas.

With the passage of time and the complexity of intra-city processes, communities become an object of study not as a spatial union, but as a social one. The evolutionary foundation is being replaced by an understanding of the mechanical construction of communities by individuals, and it was people (and not territory) who began to be perceived as the foundation of the community. In addition, there is a tendency toward the study of communities outside 
territorial boundaries, but on the contrary, communities become participants in "transterritorial processes".

In the modern understanding of urban communities, the vector is again taken to rethink the territorial sign of the formation and significance of communities - the communities formed in the framework of apartment buildings (one or several), the main connecting element of which is infrastructure, are taken into account. At the same time, alternative ideas about communities appear when close ties within small communities are replaced by a tendency towards larger communities with weakened ties between participants.

\section{Results}

According to the results of the study, the Global Shapers Community was characterized internally, its main parameters and the reasons why this community today represents one of the most widespread networks around the world are identified.

First of all, it is necessary to determine the internal structure of the device and regulate the life and activities of the hub. As noted in the paragraph above, each local (or city) hub has its own founder-curator. Respondents in the interview noted that the curator for them acts as an experienced mentor. Answering the question about the role of the curator, the shapers identified it as an important, setting the direction of the hub's movement, an important point for them is the experience of implementation and participation in complex projects. From an interview: "Thanks to her (approx. Curator) experience and professionalism, we have more opportunities to implement our own ideas."

As for the internal hierarchy of the Tomsk community, $2 / 3$ of the respondents noted the "horizontal" type of building relations. "Definitely, this is not a vertical structure. It's generally accepted that curators do not dictate what the hub should do. It all comes from the shapers proactively.

"You can do different projects, you can implement anything. At the same time, of course, there are limitations, but freedom is still characteristic. We are free in our development. We can choose our line of development, our hub, and move in this direction. "

- Here we can see the difference from the classical perception of the community in the theory of Tennis, as an exclusively hierarchical model, where each member has his own role and his own functions. Despite the seemingly hierarchical structure of the community there is a creator, curators, and shapers themselves - interactions within each community occur at a partner, non-coercive, and non-punishable level.

Touching upon the subject of internal structure, the respondents cited as an opposite example professional communities that also operate on the territory of the city and beyond. "There is a strict hierarchy. What does the hierarchy official and not quite official. Unfortunately, I do not know if this is right or wrong, but I have to live within this hierarchy. And not always, for example, some of your own, as you think, promising ideas or thoughts find support."

As for the grounds for joining this community, there are also a number of interesting points. Note that the Tomsk hub (like all others around the world) includes representatives of various fields of activity - from IT to road construction. As the main reasons for joining the community, respondents noted:

- Interest in various kinds of communities

"I am also interested in interesting communities, I am constantly interested in what is happening in the city, in various social projects."

- The desire to transfer their knowledge / skills / abilities to others and use them to improve life around

"I have always tried to teach someone something, transfer knowledge, etc. One of the aspects of my success is that someone also once taught me something, someone believed in 
me, and it is important for me to pass this on. It was one of the most important factors that I agreed to join the community because I really like the goals and positioning of GSC."

- Involvement in global processes

"It is a pleasant feeling that you don't seem to know these people, but you have a few acquaintances in other cities who, if anything, will help you at least by the principle that you are in this community

About half of the respondents made an attempt to explain the phenomenon of the community, referring, inter alia, to historical facts. "Such a form as a community is the same when countries were united in coalitions. The first were military coalitions, when countries could not physically conquer one another, territories were simply divided. Then coalitions began to appear, which began to address not only territorial issues, but also to divide the economic space, cultural, political and religious. More complex forms began to form, including managerial ones. And now, it seems to me, the same thing happens when the world becomes more complicated, and we will never know about some problems in our life, if not such a community. "In addition, the respondents put forward the hypothesis that the community is "such a large platform for exchanging experiences, to share their experiences and in order to adopt some best practices, to know about them. It is amazing what problems are being dealt with in Africa. When you see that one of the shapers has set himself the task of creating a luxury product: a bag, shoes, accessories, luxury cars in Africa, you understand that you had a stereotypical mindset about what is happening there in Africa. "The "tie" to the city turned out to be of fundamental importance for shapers. Despite the fact that all the respondents noted the plus of membership in such a community - the opportunity to be a part of world processes, the opportunity to get to know "the right" people, etc. - more than half of the respondents noted the principle of the existence and activity of the community - on the territory of the city, the opportunity to carry out activities aimed at improving the urban environment and increasing the comfort and quality of life. "The main reason for the hub's activities, of course, is that we see what is missing in the city, which requires some improvements, changes, which requires our attention. And not only ours, but also what it is necessary to draw the attention of some certain people to ".About $2 / 3$ of the respondents, while talking about the community, mentioned the word "unique" as one of the key characteristics of this community. This testifies, inter alia, to the fact that this community is of a precedent nature on a global scale. Unfortunately, over the 2 years of existence and the constantly increasing rate of expansion of the community around the world, no data has been conducted and published on the performance of both the community as a whole and local communities located in different cities. The participants of the hubs highlight the results of their activities on the official website of the community and in its official group on the social network Facebook, which makes it possible to exchange experiences with each other, cooperate in joint initiatives, give advice, etc. Therefore, the phenomenon of "uniqueness" can still be considered exclusively in the context of the idea itself and its implementation and such successful scaling.

\section{Discussion}

In 2012, on the initiative of the founder, chief ideologist and president of the World Economic Forum in Davos, which has more than 40 years of history, Klaus Schwab established a community for young people aged 20 to 30 under the name Global Shapers Community (Community of World Shapers). Professor Schwab defines the reason for the need to create this kind of community as follows: "We are increasingly aware that in solving global problems we need to more purposefully involve youth at all levels - local, regional, national and global. Because it is this generation that has the passion, dynamism and entrepreneurial spirit to shape the future." According to community organizers, today more than $50 \%$ of the 
world's population is under the age of 27 years, most of whom live in urban areas. In a study conducted by the headquarters of the World Economic Forum, it turned out that $92 \%$ of the respondents in different parts of the Earth in the corresponding age range agree that the world should change, $84 \%$ consider it their duty to make these changes, almost $82 \%$ believe that they have the power and ability to make these changes real. In addition, as the authors of the study indicate, this generation feels more confident, thanks to the existing technological opportunities for obtaining information and, as a result, the expansion of opportunities for interaction and cooperation with other people.

The GSC phenomenon is based on the general phenomenon of the World Economic Forum. Having existed for 42 years, the Davos forum has evolved from a purely academic conference into a global forum that puts the most relevant and global issues on the agenda. Each year, the forum brings together leaders of leading countries of the world, well-known figures from various fields - business, science, technology, art, etc. This is an independent international organization whose goal is to improve the state of the world by attracting the business elite, political, scientific leaders to form global, regional and sectoral agendas. Throughout its history, the WEF has had successful experience in involving young people in actively and positively influencing global issues. The initiated new global community Global Shapers Community is called upon to prepare a platform for shaping the future for young people from all over the world. In addition, the Global Shapers Community could be a precedent for a true global community, assured by its founders.

What is the global network of the Global Shapers Community? The basis of the community is the so-called hubs (hub nodes) in the capitals and large cities of most countries of the world, uniting young people who are striving to contribute to improving life at the local level. Each hub has its own founder-curator. The task of the local hub is to be a fullfledged participant in regional and global processes and a catalyst for entrepreneurship.

The participants in the hub are the shapers involved in projects related to specific problems identified by both the local hub and the Global Shapers Community leadership. Projects are discussed at regular meetings held in the regions of the world and at the WEF headquarters. But, most importantly, projects and the hub as a whole should have an impact and improve the life of the city and the region.

\section{Conclusions}

To become a member of the local Global Shapers Community, its creators have developed a number of conditions (entry procedures, characteristics that potential shapers should have, etc.). In particular, they include:

- Age: from 20 to 30 years;

- The presence of high standards of moral and mental integrity;

- The presence of unique qualities that distinguish from the mainstream;

- Experience in the business sector (experience in implementing projects, founding a company or organization);

- Willingness to participate in community life, strengthening our mission and goals of supporting our fellow shapers in personal and professional development.

Representatives of any professions aimed at developing their abilities in the interests of society can become GSC participants. They should be supporters of high moral and intellectual principles. Members of the Global Shapers Community organize centers of activity in major cities around the world - they interact with each other, exchanging experiences and ideas. Communicating with each other, Community members can put forward ideas and entrepreneurial innovations to solve pressing global problems: from improving legislation and the environment to youth employment. Community members can 
use the forum platform and opportunities for cooperation with companies - strategic partners of the WEF to put their ideas into practice.

For the city, the presence of different urban communities can become the basis for a new vector of its development, because today the cities face an important task of retaining young people, university graduates who are able not only to preserve, but also strengthen the scientific, intellectual potential of the city, become significant participants in the economic development.

\section{References}

1. F. Lamanna, M. Lenormand, M. Henar Salas-Olmedo, G. Romanillos, B. Gonçalves, J.J. Ramasco, Immigrant community integration in world cities (2018) https://doi.org/10.1371/journal.pone.0191612

2. R.I. Meneguette, G.P.R. Filho, D.L. Guidoni, G. Pessin, L.A. Villas, J., Ueyama, Experiments in Urban and Highway Environment (2016) https://doi.org/10.1371/journal.pone.0159110

3. K.A. Cagney, D. Sterrett, J. Benz, Trevor Tompso, Social Resources and Community Resilience in the Wake of Superstorm Sandy (2016) https://doi.org/10.1371/journal.pone.0160824

4. E.J. Urban, S.T. Charles, L.J. Levine, D.M. Almeida, Depression history and memory bias for specific daily emotions (2018) https://doi.org/10.1371/journal.pone.0203574

5. D.T.C. Cox, K.J. Gaston Urban Bird Feeding: Connecting People with Nature (2016) https://doi.org/10.1371/journal.pone.0158717

6. P. Salesses, K. Schechtner, C.A. Hidalgo, The Collaborative Image of The City: Mapping the Inequality of Urban Perception (2013) https://doi.org/10.1371/journal.pone.0068400

7. Y. Rafid Bahar Al-Mayouf, M. Ismail, N. Fadzilah Abdullah, et al, PLOS ONE (2016) https://doi.org/10.1371/journal.pone.0165966

8. Kee Moon Jang, Youngchul Kim, Crowd-sourced cognitive mapping: A new way of displaying people's cognitive perception of urban space (2019) https://doi.org/10.1371/journal.pone.0218590

9. Cuiying Song, Wei Guan, Jihui Ma, Potential travel cost saving in urban publictransport networks using smartphone guidance (2018) https://doi.org/10.1371/journal.pone.0197181

10. M. Bertotti, P. Watts, G. Netuveli, Ge Yu, E. Schmidt, P. Tobi, S. Lais, A. Renton, Types of Socia l Capital and Mental Disorder in Deprived Urban Areas: A Multilevel Study of 40 Disadvantaged (Neighbourhoods, London, 2013) https://doi.org/10.1371/journal.pone.0080127

11. Manami Ejiri, Hisashi Kawai, Yoshinori Fujiwara, Kazushige Ihara, Yutaka Watanabe, Hirohiko Hirano, Hun Kyung Kim, Kaori Ishii, Koichiro Oka, Shuichi Obuchi, Social participation reduces isolation among Japanese older people in urban area: A 3-year longitudinal study (2019) https://doi.org/10.1371/journal.pone.0222887

12. L. Perez, S. Dragicevic, J. Gaudreau, A geospatial agent-based model of the spatial urban dynamics of immigrant population: A study of the island of Montreal (Canada, 2019) https://doi.org/10.1371/journal.pone.0219188

13. M.M. Cullen, D. Schmitt, M.C. Granatosky, C.E. Wall, M. Platt, R. Larsen, Gazebehaviors of runners in a natural, urban running environment (2020) https://doi.org/10.1371/journal.pone.0233158 
14. M. Fonoberova, I. Mezić, J. Mezić, R. Mohr, An agent-based model of urban insurgence: Effect of gathering sites and Koopman mode analysis (2018) https://doi.org/10.1371/journal.pone.0205259

15. A. Joya Sharma, M.A. Subramanyam, Psychological wellbeing of middle-aged and older queer men in India: A mixed-methods approach (2020) https://doi.org/10.1371/journal.pone.0229893 